\title{
Safety outcomes in advanced non-small-cell lung cancer patients treated with first-line platinum-based regimens in the United States
}

\author{
Lei Chen ${ }^{1}$, Jong Seok Kim, Belen San Antonio ${ }^{2}$, Yajun Emily Zhu', Lucy Mitchell ${ }^{3}$, William John ${ }^{1 *}$ \\ ${ }^{1}$ Eli Lilly and Company, Lilly Corporate Center, Indianapolis, IN, USA; ${ }^{2}$ Eli Lilly and Company, Madrid, 28108, Spain; ${ }^{3}$ Eli Lilly and Company, Erl \\ Wood, Windlesham, Surrey, UK \\ Contributions: (I) Conception and design: All authors; (II) Administrative support: None; (III) Provision of study materials or patients: None; (IV) \\ Collection and assembly of data: All authors; (V) Data analysis and interpretation: All authors; (VI) Manuscript writing: All authors; (VII) Final \\ approval of manuscript: All authors. \\ Correspondence to: Jong Seok Kim, MD. Eli Lilly and Company, Lilly Corporate Center, Indianapolis, IN 46285, USA. Email: kim_jong_seok@lilly.com.
}

Background: We analyzed the treatment patterns and safety outcomes of the most common first-line platinum-based regimens initiated on or after non-small cell lung cancer (NSCLC) diagnosis in a real-world setting.

Methods: Based on a United States oncology electronic medical record (EMR) database, patients treated with first-line platinum-based regimens after advanced NSCLC diagnosis from September 2008 to November 2014 were analyzed. Baseline characteristics and selected adverse events during treatment [incidence proportions and incidence rates (IRs)] were described by regimen. Propensity score stratification was used to adjust for baseline characteristics differences. Hazard ratios (HRs) were estimated using Cox proportional hazards model, with paclitaxel (Pac)/carboplatin (Carbo) as reference. Subgroup analysis was conducted for elderly patients ( $\geq 70$ years old).

Results: The most common five regimens for the eligible patients were as follows: Pac/Carbo $(\mathrm{n}=3,009)$, pemetrexed (Pem)/Carbo ( $\mathrm{n}=1,625)$, Pem/Carbo/bevacizumab (Bev) (n=735), Pac/Carbo/Bev ( $\mathrm{n}=531)$, Pem/cisplatin (Cis) ( $\mathrm{n}=357)$, and docetaxel (Doc)/Carbo $(\mathrm{n}=355)$. Highest IRs were reported for anemia, neutropenia, nausea, and vomiting across these regimens in patients of all ages. After propensity score stratification, compared with $\mathrm{Pac} / \mathrm{Carbo}$, risk of anemia was significantly lower with $\mathrm{Pac} / \mathrm{Carbo} / \mathrm{Bev}$ (HR =0.67), Pem/Cis (HR =0.68), and Pem/Carbo/Bev (HR =0.82); risk of neutropenia was comparable among all regimens except Doc/Carbo (significantly lower risk; HR =0.72); and risk of nausea $(\mathrm{HR}=1.45$ ) and vomiting $(\mathrm{HR}=1.50)$ was significantly higher with $\mathrm{Pem} / \mathrm{Cis}$. Safety outcomes in elderly patients were consistent with the overall population.

Conclusions: While EMR data have limitations, the real-world safety outcome with individual chemotherapy regimen could be considered for the better selection of platinum-based therapies in NSCLC.

Keywords: Chemotherapy; elderly patients; non-small cell lung cancer (NSCLC); real-world setting; safety profile

Submitted Mar 06, 2019. Accepted for publication Sep 12, 2019.

doi: $10.21037 /$ jtd.2019.11.11

View this article at: http://dx.doi.org/10.21037/jtd.2019.11.11

\footnotetext{
* Current Affiliation: Abbvie Inc., 1 North Waukegan Rd., North Chicago, IL 60064, USA
} 


\section{Introduction}

Non-small cell lung cancer (NSCLC) accounts for $80 \%$ to $85 \%$ of all lung cancer $(222,500$ new cases per year in the United States) (1), and the predominant proportion of the patients $(80 \%)$ are ultimately diagnosed as stage IV disease (1-3). Until the recent emergence of immune checkpoint inhibitors (ICIs), platinum-based chemotherapy has been the gold standard for the first-line treatment of patients with advanced NSCLC without EGFR mutation or ALK/ROS1 rearrangement $(4,5)$. Still, as a current standard of care in NSCLC patients without a targetable gene aberration, platinum doublet chemotherapy is actively studied in combination with various ICIs (6-8). ECOG 1594 study proved four platinum doublet chemotherapy (cisplatin and paclitaxel, cisplatin and gemcitabine, cisplatin and docetaxel, carboplatin and paclitaxel) were not significantly different in clinical benefit (9). Several anti-cancer targeted agents were tested in combination with these chemotherapy regimens for the initial treatment of NSCLC. Adding bevacizumab, an angiogenesis inhibitor, to carboplatin plus paclitaxel improved overall survival in the first-line treatment of patients with non-squamous NSCLC if there are no contraindications (10). Docetaxel plus platinum combination therapy is an effective treatment option with a favorable therapeutic index for first-line treatment of advanced or metastatic NSCLC (11). Pemetrexed-based combination chemotherapy represents a therapeutic option in patients with advanced non-squamous NSCLC (12-15).

Although there are a number of available platinum based treatment options, toxicity is a major concern when clinicians select their regimen (16-18). The accumulated data support the treatment guidelines to consider tumor histology, performance status, age, and comorbidities in association with the expected safety profile of a particular regimen at the time of regimen selection for individual patients (4).

The pattern of commonly used platinum-based regimens in routine clinical practice and their safety profiles have not been sufficiently investigated in the United States population. In this retrospective observational study, data from Integrated Medical Services (IMS) Oncology electronic medical records (EMR), a United States oncology clinic-based EMR database, were analyzed to determine the safety outcomes of first-line platinum-based therapy in patients with locally advanced or metastatic NSCLC.

\section{Methods}

\section{Study design and data source}

Data for this retrospective, observational, cohort study were extracted from IMS's private-practice Oncology databases of longitudinal, patient-level EMR, hospital charge data, and medical and pharmacy claims collected from physicians and other healthcare providers across the 50 states in the United States. Patient-level EMR were collected from about 550 treating providers representing 344 locations from 37 states in the United States. Data in the databases were de-identified, and the databases were certified as being compliant with the Health Insurance Portability and Accountability Act. This study was exempt from institutional review board approval because it was retrospective, did not involve any intervention, and used anonymized data. Given the nature of structured administrative data in the database, medical conditions captured were considered to be severe conditions requiring medical attention; less severe conditions might not have been recorded. Grade or severity of disease, performance status, frailty, and laboratory abnormalities were not available. The analysis included demographic and clinical characteristics of the eligible patients and incidence proportions and incidence rates (IRs) of the safety outcomes among the eligible patients, by chemotherapy regimens. The IRs, rate differences, and hazard ratios (HRs) of safety outcomes between the chemotherapy regimens were also estimated by adjusting patients' demographic and clinical characteristics for groups with adequate sample sizes. We also conducted subgroup analysis for patients $\geq 70$ years old to further examine the safety profiles of the eligible patients treated with each chemotherapy regimen in elderly patients (70 years or older) with adequate data. Additional analysis at 3,6 , and 9 months after the last dose was also conducted to determine the exposure risk during the follow-up period.

The key patient eligibility criteria included the following: (I) diagnosis of lung cancer, excluding small cell lung cancer; (II) locally advanced or metastatic disease (Stage IIIB/IV); (III) platinum-based first-line treatments initiated after advanced lung cancer diagnosis, with at least 100 eligible patients for each regimen in the database, the first date of administration of the treatments being the index date, and receiving the indexed treatment between September 26, 2008 and November 30, 2014; (IV) $\geq 18$ years on index date; and (V) stable oncology practice for patient's 
study physician between the index date and the end of the observation. The observation period was defined as between the index date until the occurrence of the adverse event of interest; 30 days after the last dose of the study drugs; an administration/prescription record indicating a switch from the study medicines to another systemic treatment; end of patient record in the database; or December 31, 2014, whichever occurred first.

\section{Data assessment}

Data were assessed by patients' baseline characteristics and clinical characteristics during treatment, including demographics, cancer diagnoses, comorbidity conditions (any cardiovascular disease, cerebrovascular disease, chronic pulmonary disease, congestive heart failure, dementia, hemiplegia or paraplegia, liver disease, myocardial infarction, peptic ulcer disease, peripheral vascular disease, renal disease, rheumatologic disease, type 2 diabetes, and type 2 diabetes with chronic issues), diagnoses recorded up to 6 months prior to the index date, medications recorded up to 3 months prior to the index, and selected adverse events diagnosed during the on-treatment period. The adverse events were selected based on literature and clinical interest of targeted treatments and disease. Adverse events with an IR $\geq 1$ per 100 person-years in each treatment group of the overall population were further analyzed by the adjusted analysis. Comorbidities and adverse events were identified from the structured EMR data using ICD-9-CM diagnosis codes.

\section{Statistical analysis}

The results were reported as descriptive analysis in counts and proportions for categorical variables, and means, standard deviations, and median for continuous variables. Propensity score stratification was used to adjust for baseline differences in potential confounding factors, which included patients' gender, race, age, cancer stage and histology, underlying comorbidities, and medical history with previous anti-cancer treatment or supportive care. Time to first occurrence of AE was conducted utilizing survival analysis. HRs with $95 \%$ confidence intervals were estimated using Cox proportional hazards regression model with paclitaxel/carboplatin as reference and stratified by propensity score quintiles. Propensity score matching was applied as a sensitivity analysis. Subgroup analyses were performed for elderly patients ( $\geq 70$ years old).

\section{Results}

\section{Patient characteristics}

The 6 eligible first-line platinum-based regimens (each with at least 100 eligible advanced NSCLC-treated patients) in the database during the study period were paclitaxel/ carboplatin (Pac/Carbo), docetaxel/carboplatin (Doc/ Carbo), pemetrexed/carboplatin (Pem/Carbo), pemetrexed/ cisplatin (Pem/Cis), paclitaxel/carboplatin/bevacizumab (Pac/Carbo/Bev), and pemetrexed/carboplatin/bevacizumab (Pem/Carbo/Bev). A total of 6,612 eligible NSCLC patients were identified.

Baseline characteristics of each regimen group, including comorbidities and a summary of prior treatments for each cohort are presented in Table 1. Patient distribution among the 6 regimens were Pac/Carbo ( $n=3,009 ; 43 \%$ elderly), Pem/Carbo ( $\mathrm{n}=1,625 ; 40 \%$ elderly), Pem/Carbo/ Bev ( $\mathrm{n}=735 ; 35 \%$ elderly), Pac/Carbo/Bev ( $=531 ; 34 \%$ elderly), Pem/Cis ( $\mathrm{n}=357 ; 19 \%$ elderly), and Doc/Carbo $(\mathrm{n}=355 ; 44 \%$ elderly). The median age (62.0-68.3 years) and the gender $(50.3-58.2 \%$ male) were similar across the groups. The majority of patients (95.5-99.1\%) had Stage IV disease across all groups. Diagnoses of any comorbidities were found in a small percentage of patients, and the proportion was similar (7.3-8.7\%) across all groups. Chronic pulmonary disease (2.8-4.5\%), type 2 diabetes $(0.8-3.1 \%)$, and renal diseases $(0.8-2.3 \%)$ were the most common comorbidities across the group in patients of all ages. The other comorbidities were found in $<1 \%$ of each treatment group. Less than $10 \%$ of patients in each group had received prior chemotherapy, biologics, or supportive care drugs prior to index. Elderly patients were less likely to receive prior chemotherapy or biologic treatments as cancer treatment prior to index compared to the patients of all ages (data not shown).

\section{Adverse events}

Crude incidence proportions and IRs of selected adverse events in patients of all ages and elderly ( $\geq 70$ years) patients are shown in Table 2 and Table 3, respectively. The most frequently diagnosed adverse events in all groups were anemia (17.7-30.6\%), neutropenia (15.2-21.0\%), nausea (9.3-20.7\%), and vomiting (8.5-18.2\%). Among all adverse events analyzed, IRs per 100 person-years during treatments were highest for anemia (36.6-73.4), neutropenia (24.549.2), nausea (13.2-30.4), and vomiting (12.0-25.8) across the groups. Similarly, the IRs for anemia and neutropenia 
Table 1 Baseline characteristics among the NSCLC patients in 6 groups representing commonly used platinum-based regimens in the United States

\begin{tabular}{|c|c|c|c|c|c|c|}
\hline \multirow[b]{2}{*}{ Categories } & \multicolumn{6}{|c|}{ First-line platinum chemotherapy combination regimen (\%) } \\
\hline & $\begin{array}{c}\text { Pac/Carbo } \\
(\mathrm{N}=3,009)\end{array}$ & $\begin{array}{c}\mathrm{Pac} / \mathrm{Carbo} / \mathrm{Bev} \\
(\mathrm{N}=531)\end{array}$ & $\begin{array}{c}\text { Doc/Carbo } \\
(\mathrm{N}=355)\end{array}$ & $\begin{array}{l}\text { Pem/Carbo } \\
(\mathrm{N}=1,625)\end{array}$ & $\begin{array}{l}\mathrm{Pem} / \mathrm{Cis} \\
(\mathrm{N}=357)\end{array}$ & $\begin{array}{c}\text { Pem/Carbo/Bev } \\
(\mathrm{N}=735)\end{array}$ \\
\hline Mean $[S D]$ & $67.2[9.7]$ & $65.3[9.4]$ & $68.0[9.3]$ & $66.7[9.9]$ & $61.4[9.6]$ & $65.5[9.7]$ \\
\hline Median $[\mathrm{IQR}]$ & $68.2[60.5-74.8]$ & $66.3[59.3-72.1]$ & $68.3[61.5-75.9]$ & $67.4[60.1-74.2]$ & $62.0[55.1-68.6]$ & $66.2[58.7-72.5]$ \\
\hline Male & $1,751(58.2)$ & $295(55.6)$ & $205(57.8)$ & $818(50.3)$ & $190(53.2)$ & $397(54.0)$ \\
\hline Female & $1,258(41.8)$ & $236(44.4)$ & $150(42.3)$ & $807(49.7)$ & $167(46.8)$ & $338(46.0)$ \\
\hline \multicolumn{7}{|l|}{ Staging } \\
\hline Any comorbidities & $237(7.9)$ & $40(7.5)$ & $31(8.7)$ & $119(7.3)$ & $28(7.8)$ & $58(7.9)$ \\
\hline Cerebrovascular disease & $11(0.4)$ & $1(0.2)$ & $2(0.6)$ & $4(0.3)$ & $1(0.3)$ & $5(0.7)$ \\
\hline Chronic pulmonary disease & $126(4.2)$ & $20(3.8)$ & $14(3.9)$ & $58(3.6)$ & $10(2.8)$ & $33(4.5)$ \\
\hline Peripheral vascular disease & $7(0.2)$ & $1(0.2)$ & $2(0.6)$ & $6(0.4)$ & $2(0.6)$ & $3(0.4)$ \\
\hline Renal disease & $50(1.7)$ & $12(2.3)$ & $6(1.7)$ & $21(1.3)$ & $5(1.4)$ & $6(0.8)$ \\
\hline Rheumatologic disease & $7(0.2)$ & $3(0.6)$ & $1(0.3)$ & $2(0.1)$ & $2(0.6)$ & $5(0.7)$ \\
\hline
\end{tabular}

Bev, bevacizumab; Carbo, carboplatin; Cis, cisplatin; Doc, docetaxel; IQR, interquartile range; N, total number of patients identified in each regimen; $n$, number of patients in each category; Pac, paclitaxel; Pem, pemetrexed; SD, standard deviation. ${ }^{a}$, comorbidities examined were any cardiovascular disease, cerebrovascular disease, chronic pulmonary disease, congestive heart failure, dementia, hemiplegia or paraplegia, liver disease, myocardial infarction, peptic ulcer disease, peripheral vascular disease, renal disease, rheumatologic disease, type 2 diabetes, and type 2 diabetes with chronic issues. Only the diseases with at least 1 patient diagnosed in each treatment group were shown

were high across the treatment groups in elderly patients. The IRs for nausea (18.7-28.7) and vomiting (16.0-27.7) were high $(\geq 10 \%)$ for all treatment groups in the elderly except the Doc/Carbo group ( $\leq 7.2)$. The crude incidence proportions of selected adverse events at 3 months, 6 months, and 9 months after the last dose in patients of all ages and elderly patients were consistent with the results presented in Table 2 and Table 3, respectively (results not shown, available upon request). We also examined the use of supportive care medications including erythropoiesis stimulating agent (ESA) and granulocyte-colony stimulating factor (G-CSF), however without knowing the administration timing of those agents, we could not interpret any relationship between the supportive care and adverse events (Tables $S 1, S 2$ ).

Adjusted HRs and $\mathrm{P}$ values (Pac/Carbo as reference) among patients of all ages and elderly patients ( $\geq 70$ years) after propensity score stratification are presented in Table 4 and Table 5, respectively. In patients of all ages, the risk of anemia was significantly lower $(\mathrm{P}<0.05)$ in $\mathrm{Pac} / \mathrm{Carbo} /$ Bev $(\mathrm{HR}=0.67), \mathrm{Pem} / \mathrm{Cis}(\mathrm{HR}=0.68)$, and Pem/Carbo/ Bev ( $\mathrm{HR}=0.82)$ groups as compared to the reference (Pac/ Carbo) group. The risk of neutropenia was comparable among all groups except the Doc/Carbo group (significantly 
Table 2 Crude incidence proportions (\%) and incidence rates of selected adverse events among the NSCLC patients of all ages in 6 groups representing commonly used platinum-based regimens in the United States

\begin{tabular}{|c|c|c|c|c|c|c|c|c|c|c|c|c|}
\hline \multirow[b]{2}{*}{ Adverse events } & \multicolumn{2}{|c|}{ Pac/Carbo } & \multicolumn{2}{|c|}{$\mathrm{Pac} / \mathrm{Carbo} / \mathrm{Bev}$} & \multicolumn{2}{|c|}{ Doc/Carbo } & \multicolumn{2}{|c|}{ Pem/Carbo } & \multicolumn{2}{|c|}{$\mathrm{Pem} / \mathrm{Cis}$} & \multicolumn{2}{|c|}{ Pem/Carbo/Bev } \\
\hline & n (\%) & $\begin{array}{l}\text { IR per } \\
100 \mathrm{PY}\end{array}$ & n (\%) & $\begin{array}{l}\text { IR per } \\
100 \mathrm{PY}\end{array}$ & n (\%) & $\begin{array}{l}\text { IR per } \\
100 \mathrm{PY}\end{array}$ & n (\%) & $\begin{array}{l}\text { IR per } \\
100 \mathrm{PY}\end{array}$ & n (\%) & $\begin{array}{l}\text { IR per } \\
100 \mathrm{PY}\end{array}$ & $\mathrm{n}(\%)$ & $\begin{array}{l}\text { IR per } \\
100 \mathrm{PY}\end{array}$ \\
\hline \multicolumn{13}{|l|}{ Hematologic events } \\
\hline Anemia & $922(30.6)$ & 60.47 & $94(17.7)$ & 45.07 & $105(29.6)$ & 51.93 & $478(29.4)$ & 73.38 & $87(24.4)$ & 36.61 & $175(23.8)$ & 65.80 \\
\hline Thrombocytopenia & $82(2.7)$ & 4.09 & $7(1.3)$ & 2.84 & $9(2.5)$ & 3.52 & $52(3.2)$ & 5.76 & $12(3.4)$ & 4.11 & $12(1.6)$ & 3.72 \\
\hline \multicolumn{13}{|l|}{$\begin{array}{l}\text { Non-hematologic } \\
\text { events }\end{array}$} \\
\hline Infection & $114(3.8)$ & 5.71 & $26(4.9)$ & 10.77 & $8(2.3)$ & 3.08 & $56(3.4)$ & 6.20 & $24(6.7)$ & 8.41 & $15(2.0)$ & 4.64 \\
\hline Diarrhea & $44(1.5)$ & 2.18 & $10(1.9)$ & 4.05 & $3(0.8)$ & 1.16 & $19(1.2)$ & 2.06 & $10(2.8)$ & 3.43 & $5(0.7)$ & 1.54 \\
\hline Nausea & $418(13.9)$ & 22.38 & $59(11.1)$ & 25.64 & $33(9.3)$ & 13.19 & $208(12.8)$ & 24.55 & $74(20.7)$ & 30.36 & $84(11.4)$ & 27.85 \\
\hline Vomiting & $353(11.7)$ & 18.58 & $52(9.8)$ & 22.30 & $30(8.5)$ & 11.96 & 185 (11.4) & 21.58 & 65 (18.2) & 25.83 & 75 (10.2) & 24.68 \\
\hline
\end{tabular}

Bev, bevacizumab; Carbo, carboplatin; Cis, cisplatin; Doc, docetaxel; IR, incidence rate; $N$, total number of patients identified in each regimen; $n$, number of patients in each category; NSCLC, non-small cell lung cancer; Pac, paclitaxel; Pem, pemetrexed; PY, person-years. Only adverse events with an incidence rate $\geq 1$ per $100 \mathrm{PY}$ in every treatment group of all ages shown.

Table 3 Crude incidence proportions (\%) and incidence rates of selected adverse events among the elderly NSCLC patients in 6 groups representing commonly used platinum-based regimens in the United States

\begin{tabular}{|c|c|c|c|c|c|c|c|c|c|c|c|c|}
\hline \multirow[b]{2}{*}{ Adverse events } & \multicolumn{2}{|c|}{ Pac/Carbo } & \multicolumn{2}{|c|}{$\mathrm{Pac} / \mathrm{Carbo} / \mathrm{Bev}$} & \multicolumn{2}{|c|}{ Doc/Carbo } & \multicolumn{2}{|c|}{ Pem/Carbo } & \multicolumn{2}{|c|}{$\mathrm{Pem} / \mathrm{Cis}$} & \multicolumn{2}{|c|}{ Pem/Carbo/Bev } \\
\hline & n (\%) & $\begin{array}{l}\text { IR per } \\
100 \mathrm{PY}\end{array}$ & $\mathrm{n}(\%)$ & $\begin{array}{l}\text { IR per } \\
100 \mathrm{PY}\end{array}$ & $\mathrm{n}(\%)$ & $\begin{array}{l}\text { IR per } \\
100 \mathrm{PY}\end{array}$ & n (\%) & $\begin{array}{l}\text { IR per } \\
100 \mathrm{PY}\end{array}$ & n (\%) & $\begin{array}{l}\text { IR per } \\
100 \mathrm{PY}\end{array}$ & n (\%) & $\begin{array}{l}\text { IR per } \\
100 \mathrm{PY}\end{array}$ \\
\hline \multicolumn{13}{|l|}{ Hematologic events } \\
\hline Anemia & 432 (33.3) & 69.66 & $26(14.6)$ & 60.88 & $52(33.5)$ & 66.05 & 189 (29.1) & 69.53 & $20(29.9)$ & 41.12 & 60 (23.4) & 70.06 \\
\hline Thrombocytopenia & $32(2.5)$ & 3.77 & 0 & 0 & $6(3.9)$ & 5.42 & $21(3.2)$ & 5.58 & $1(1.5)$ & 1.55 & $3(1.2)$ & 2.87 \\
\hline \multicolumn{13}{|l|}{ Non-hematologic events } \\
\hline Infection & $45(3.5)$ & 5.29 & $2(1.1)$ & 3.92 & 0 & 0 & $18(2.8)$ & 4.68 & $4(6.0)$ & 6.60 & $6(2.3)$ & 5.72 \\
\hline Thromboembolic events & $51(3.9)$ & 5.95 & $2(1.1)$ & 3.88 & $9(5.8)$ & 8.39 & $29(4.5)$ & 7.63 & $3(4.5)$ & 4.66 & $4(1.6)$ & 3.85 \\
\hline Vomiting & $130(10.0)$ & 15.95 & $12(6.7)$ & 23.98 & $7(4.5)$ & 6.30 & $72(11.1)$ & 19.80 & $14(20.9)$ & 27.71 & $20(7.8)$ & 20.56 \\
\hline
\end{tabular}

Bev, bevacizumab; Carbo, carboplatin; Cis, cisplatin; Doc, docetaxel; IR, incidence rate; $N$, total number of patients identified in each regimen; $n$, number of patients in each category; NSCLC, non-small cell lung cancer; Pac, paclitaxel; Pem, pemetrexed; PY, person-years. 
Table 4 Adjusted hazard ratios (Pac/Carbo as reference) among the NSCLC patients of all ages after propensity score stratification in 6 groups representing commonly used platinum-based regimens in the United States

\begin{tabular}{|c|c|c|c|c|c|c|c|c|c|c|c|}
\hline Adverse events & Pac/Carbo & \multicolumn{2}{|c|}{$\mathrm{Pac} / \mathrm{Carbo} / \mathrm{Bev}$} & \multicolumn{2}{|c|}{ Doc/Carbo } & \multicolumn{2}{|c|}{ Pem/Carbo } & \multicolumn{2}{|c|}{$\mathrm{Pem} / \mathrm{Cis}$} & \multicolumn{2}{|c|}{ Pem/Carbo/Bev } \\
\hline All ages & $\mathrm{N}=3,009$ & \multicolumn{2}{|c|}{$N=531$} & \multicolumn{2}{|c|}{$\mathrm{N}=355$} & \multicolumn{2}{|c|}{$\mathrm{N}=1,625$} & \multicolumn{2}{|c|}{$\mathrm{N}=357$} & \multicolumn{2}{|c|}{$\mathrm{N}=735$} \\
\hline \multicolumn{12}{|l|}{ Hematologic events } \\
\hline Anemia & 920 & 94 & $0.67^{c}$ & 105 & 0.89 & 477 & 1.07 & 87 & $0.68^{c}$ & 175 & $0.82^{c}$ \\
\hline Thrombocytopenia & 82 & 7 & 0.62 & 9 & 0.88 & 52 & 1.32 & 12 & 1.08 & 12 & 0.74 \\
\hline \multicolumn{12}{|l|}{ Non-hematologic events } \\
\hline Infection & 114 & 25 & $1.54^{\mathrm{c}}$ & 8 & 0.55 & 56 & 1.01 & 24 & 1.51 & 15 & 0.66 \\
\hline Thromboembolic events & 124 & 14 & 0.82 & 18 & 1.20 & 75 & 1.27 & 28 & $1.69^{c}$ & 16 & 0.64 \\
\hline Vomiting & 353 & 50 & 1.06 & 30 & 0.69 & 185 & 1.17 & 65 & $1.50^{\mathrm{c}}$ & 75 & 1.18 \\
\hline
\end{tabular}

Bev, bevacizumab; Carbo, carboplatin; Cis, cisplatin; Doc, docetaxel; HR, hazard ratio; N, total number of patients identified in each regimen; $n$, number of patients in each category; NSCLC, non-small cell lung cancer; Pac, paclitaxel; Pem, pemetrexed. ', only HRs of adverse events with an incidence rate $\geq 1$ per 100 person-years (see Table 1) in every treatment group of all ages shown. ' HRs were calculated using Pac/Carbo ( $\mathrm{N}=3,009$ for all ages) as reference. ${ }^{\mathrm{c}} \mathrm{P}$ value $\leq 0.05$.

lower risk; $\mathrm{P}<0.05, \mathrm{HR}=0.72)$. The risk of nausea ( $\mathrm{HR}=1.45)$, vomiting $(\mathrm{HR}=1.50)$, and thromboembolic events $(\mathrm{HR}=1.69)$ was significantly higher $(\mathrm{P}<0.05)$ in the Pem/Cis group. The risk of hematological and gastrointestinal adverse events was similar $(\mathrm{P}>0.05)$ between Pac/Carbo and Pem/Carbo, the 2 most common regimens.

The trends for adverse events in elderly patients with sufficient numbers were generally consistent with patients of all ages (Tables 4,5$)$. The risk of anemia was significantly lower $(\mathrm{P}<0.05)$ with $\mathrm{Pac} / \mathrm{Carbo} / \mathrm{Bev}(\mathrm{HR}=0.60)$, and numerically lower with $\mathrm{Pem} / \mathrm{Carbo} / \mathrm{Bev}(\mathrm{HR}=0.77$, $\mathrm{P}=0.06)$. The risk of hematological and gastrointestinal adverse events was similar between elderly populations in the Pac/Carbo and Pem/Carbo groups. The adjusted HRs were not shown for elderly patients in the Pem/ Cis group due to the small number of patients in this subgroup $(\mathrm{n}=67)$ and the associated insufficient statistical power. The hazard ratios at 3 months, 6 months, and 9 months after the last dose for patients of all ages and the elderly were consistent with the results presented in Table 3 and Table 4, respectively (results not shown). The incidence rates of hypertension and haemorrhage were numerically higher in the bevacizumab-containing treatment groups;
$\mathrm{Pac} / \mathrm{Carbo} / \mathrm{Bev}$ had a numerically higher incidence of those two adverse events compared to Pem/Carbo/Bev group (3.27, 4.95 vs. $0.93,3.14$, respectively; Tables $S 1, S 2$ ).

\section{Discussion}

The results of this retrospective cohort analysis from United States EMR data collected from the routine clinical practice setting confirmed that carboplatin has been the preferred platinum prescribed overall in NSCLC patients and in elderly patients. Our analysis showed that only $19 \%$ of patients receiving cisplatin-based chemotherapy (Pem/ Cis) were elderly compared with $34 \%$ to $44 \%$ of patients receiving carboplatin-based regimens, which could indicate that cisplatin is not the preferred component for the elderly. Though the benefits of survival and tumor response of cisplatin over carboplatin have been reported previously $(15,19)$, the results were either derived from unspecified subgroup analysis of a small subgroup of patients (15) or from retrospective analysis (19). Given the low level of clinical evidence, the efficacy of cisplatin versus carboplatin for the chemotherapy combination is still debatable, and as our study indicates, most US physicians prefer 
Table 5 Adjusted hazard ratios (Pac/Carbo as reference) among the elderly NSCLC patients after propensity score stratification in 6 groups representing commonly used platinum-based regimens in the United States

\begin{tabular}{|c|c|c|c|c|c|c|c|c|c|c|c|}
\hline Adverse events & Pac/Carbo & \multicolumn{2}{|c|}{ Pac/Carbo/Bev } & \multicolumn{2}{|c|}{ Doc/Carbo } & \multicolumn{2}{|c|}{ Pem/Carbo } & \multicolumn{2}{|c|}{$\mathrm{Pem} / \mathrm{Cis}$} & \multicolumn{2}{|c|}{ Pem/Carbo/Bev } \\
\hline Elderly ( $\geq 70$ years) & $\mathrm{N}=1,296$ & \multicolumn{2}{|c|}{$\mathrm{N}=178$} & \multicolumn{2}{|c|}{$N=155$} & \multicolumn{2}{|c|}{$N=650$} & \multicolumn{2}{|c|}{$\mathrm{N}=67$} & \multicolumn{2}{|c|}{$\mathrm{N}=256$} \\
\hline \multicolumn{12}{|l|}{ Hematologic events } \\
\hline Anemia & 430 & 26 & $0.60^{d}$ & 52 & 0.97 & 189 & 0.93 & - & - & 60 & 0.77 \\
\hline Thrombocytopenia & 32 & 0 & - & 6 & 1.50 & 21 & 1.41 & - & - & 3 & 0.60 \\
\hline \multicolumn{12}{|l|}{ Non-hematologic events } \\
\hline Infection & 45 & 2 & 0.58 & 0 & - & 18 & 0.86 & - & - & 6 & 0.92 \\
\hline Thromboembolic events & 51 & 2 & 0.52 & 9 & 1.42 & 29 & 1.23 & - & - & 4 & 0.52 \\
\hline Nausea & 150 & 13 & 1.07 & 8 & $0.42^{d}$ & 82 & 1.24 & - & - & 21 & 0.99 \\
\hline Vomiting & 130 & 11 & 1.08 & 7 & $0.43^{\mathrm{d}}$ & 72 & 1.27 & - & - & 20 & 1.14 \\
\hline
\end{tabular}

Bev, bevacizumab; Carbo, carboplatin; Cis, cisplatin; Doc, docetaxel; HR, hazard ratio; N, total number of patients identified in each regimen; n, number of patients in each category; NSCLC, non-small cell lung cancer; Pac, paclitaxel; Pem, pemetrexed. ', for elderly patients, only hazard ratios of adverse events with $n \geq 5$ (see Table 1) in individual treatment group shown. 'HRs were calculated using Pac/Carbo ( $\mathrm{N}=1,296$ for elderly) as reference. ${ }^{\circ}$, adjusted HR estimates are not shown because the total number of elderly patients treated with first-line Pem/Cis in the database $(n=67)$ is small and thus lacks statistical power. ${ }^{d}, P$ value $\leq 0.05$.

to use carboplatin rather than cisplatin for the doublet chemotherapy in NSCLC treatment. In our study, patients receiving Pem/Cis, including the elderly population, had a lower IR of anemia than patients receiving a carboplatin doublet. However, given the small number of elderly patients receiving Pem/Cis, it was not feasible to further assess the anemia risk for this subgroup in the adjusted analysis.

Anemia, neutropenia, nausea, and vomiting were observed to be the most common adverse events in the patient groups receiving these treatments. However, the IR for thromboembolic events was similar to nausea and vomiting in the elderly patients treated with Doc/Carbo. The observed IR was higher for anemia and neutropenia in elderly patients than in patients of all ages for most treatment groups; it was, however, comparable for anemia in the Pem/Carbo group and neutropenia in the Doc/Carbo and Pem/Carbo groups. The IRs of other adverse events were comparable between elderly patients and patients of all ages. The consistent safety outcomes between elderly patients and the population of all ages aligns with recent publications in the sense that treatment in the elderly should not solely be based on age (20-22).

The Pem/Cis regimen group, the only cisplatin-based regimen, had a numerically higher proportion of patients diagnosed with thromboembolic events (7.8\%) compared to the other regimens consisting of carboplatin (2.2-5.1\%). These results are consistent with the findings from a retrospective study that used hospital records of all patients with NSCLC from 2000 through 2012, which reported that $7.9 \%$ of the cisplatin-treated patients and $4.2 \%$ of carboplatin-treated patients in a first-line setting were diagnosed with thromboembolic events (23). The observed higher frequency of thromboembolic events in the Pem/ Cis group than in all the carboplatin-based regimen groups in this study may reflect the differences between the risks associated with the 2 platinum backbones.

The adjusted analysis among patients of all ages after propensity score stratification provided additional information on the risk of adverse events for patients treated with different regimens compared with patients treated with Pac/Carbo: anemia was significantly lower in $\mathrm{Pac} / \mathrm{Carbo} / \mathrm{Bev}, \mathrm{Pem} / \mathrm{Cis}$, and Pem/Carbo/Bev groups; neutropenia was comparable among all groups except the 
Doc/Carbo group; nausea, vomiting, and thromboembolic events were significantly higher in the Pem/Cis group. Overall, the adjusted analysis indicated that hematological and gastrointestinal adverse events were similar between the 2 most commonly used regimens (Pac/Carbo and Pem/ Carbo). Additional analysis with the varying duration of follow-up after the last dose showed consistency with the overall results.

Our results indicate that $\mathrm{Pem} / \mathrm{Carbo} / \mathrm{Bev}$ has a lower incidence of adverse events overall than Pem/ Carbo alone. However, we aimed to focus on common toxicities related to chemotherapeutic agents and did not include some bevacizumab-associated adverse events such as haemorrhage, hypertension, and pain, as part of our main safety analysis. Thus, it does not lead to our interpretation that bevacizumab-containing chemotherapy (triplet) regimens have better tolerability than platinum doublet chemotherapy overall. Multiple clinical trials have previously proven that bevacizumab in combination with platinum-based chemotherapy provide improved efficacy benefit in patients with advanced nonsquamous NSCLC (12,24-26). However, with no available predictive biomarkers for bevacizumab, the choice of treatment should be based on clinical factors of individual patients. Given the nature of structured administrative data in the database, medical conditions captured were considered severe, requiring medical attention, and less severe conditions might not have been recorded. Although, we did not collect performance status (ECOG PS), lab abnormality, frailty, and severity of disease at the baseline, it is possible that patients in the Pem/Carbo group were more fragile in organ function and performance status which might have affected the development of toxicity.

A few limitations of our study warrant careful consideration. The severity of adverse events and patient performance status were not recorded in the database. Given that the captured medical conditions in the EMR were considered severe enough to require medical attention, less severe conditions may not have been recorded. The small number of elderly patients with adverse events other than anemia, neutropenia, nausea, and vomiting further limited the study power for the adjusted analyses in our elderly population. Carboplatin was the most commonly prescribed platinum in the overall NSCLC patients and in elderly patients in the US during the indexed treatment period. Prospective studies on the survival benefits of cisplatin $v s$. carboplatin with focus on performance status and outcome are still lacking.
The safety versus tumor histology was not analyzed since the histology was not captured in these populations. Finally, the EMR data for this study did not contain accurate death dates, which prevented accurate evaluation of treatmentrelated deaths and assessment of survival benefit associated with the 6 regimens.

Despite the limitations associated with EMR data and the retrospective design of the study, these results provided additional information about safety profiles for common platinum-based doublet therapies that may help clinicians make informed treatment decisions. The results from this analysis are helpful to understand the impact of combination therapy in patients of all ages and in elderly patients since platinum doublets in combination with targeted therapies have the potential to increase toxicity in elderly patients $(20,22)$. Given that lung cancer mainly occurs in older people, further analysis in a large number of elderly patients treated with these regimens will be needed to determine the optimal combination therapy for patients with NSCLC.

\section{Acknowledgments}

Eli Lilly and Company was involved in the study design, data collection, and data analysis. Medical writing support was provided by Ira Ayene, $\mathrm{PhD}$, of Syneos Health, funded by Eli Lilly and Company. This work was presented in part as a poster at IASLC Chicago Multidisciplinary Symposium in Thoracic Oncology; Chicago, IL; September 22-24, 2016. This study was funded by Eli Lilly and Company.

\section{Footnote}

Conflicts of Interest: L Chen, JS Kim, B San Antonio, YE Zhu, L Mitchell, W John are current/former employees and own stock in Eli Lilly and Company.

Ethical Statement: The authors are accountable for all aspects of the work and for ensuring that questions related to the accuracy or integrity of any part of the work are appropriately investigated and resolved. This study was exempt from institutional review board approval because it was retrospective, did not involve any intervention, and used anonymized data.

\section{References}

1. American Cancer Society (2016) About non-small cell lung cancer. Available online: http://www.cancer.org/ 
content/dam/CRC/PDF/Public/8703.00.pdf. Accessed 28 June 2017.

2. National Cancer Institute (2017) SEER Cancer stat facts: lung and bronchus cancer. Available online: http:// seer.cancer.gov/statfacts/html/lungb.html. Accessed 28 June 2017.

3. Scheff RJ, Schneider BJ. Non-small-cell lung cancer: treatment of late stage disease: chemotherapeutics and new frontiers. Semin Intervent Radiol 2013;30:191-8.

4. Peters S, Adjei AA, Gridelli C, et al. ESMO Guidelines Working Group Metastatic non-small-cell lung cancer (NSCLC): ESMO Clinical Practice Guidelines for diagnosis, treatment and follow-up. Ann Oncol 2012;23 suppl 7:vii56-64.

5. Reck M, Popat S, Reinmuth N, et al. ESMO Guidelines Working Group Metastatic non-small-cell lung cancer (NSCLC): ESMO Clinical Practice Guidelines for diagnosis, treatment and follow-up. Ann Oncol 2014;25 suppl 3:iii27-39.

6. Langer CJ, Gadgeel SM, Borghaei H, et al. Carboplatin and pemetrexed with or without pembrolizumab for advanced, non-squamous non-small-cell lung cancer: a randomised, phase 2 cohort of the open-label KEYNOTE-021 study. Lancet Oncol 2016;17:1497-508.

7. Seetharamu N, Preeshagul IR, Sullivan KM. New PDL1 inhibitors in non-small-cell lung cancer - impact of atezolizumab. Lung Cancer (Auckl) 2017;8:67-78.

8. Thatcher N, Hirsch FR, Luft AV, et al. Necitumumab plus gemcitabine and cisplatin versus gemcitabine and cisplatin alone as first-line therapy in patients with stage IV squamous non-small-cell lung cancer (SQUIRE): an open-label, randomised, controlled phase 3 trial. Lancet Oncol 2015;16:763-74.

9. Schiller JH, Harrington D, Belani CP, et al. Eastern Cooperative Oncology Group Comparison of four chemotherapy regimens for advanced non-small-cell lung cancer. N Engl J Med 2002;346:92-8.

10. Sandler A, Gray R, Perry MC, et al. Paclitaxel-carboplatin alone or with bevacizumab for non-small-cell lung cancer. N Engl J Med 2006;355:2542-50.

11. Fossella F, Pereira JR, von Pawel J, et al. Randomized, multinational, phase III study of docetaxel plus platinum combinations versus vinorelbine plus cisplatin for advanced non-small-cell lung cancer: the TAX 326 study group. J Clin Oncol 2003;21:3016-24.

12. Patel JD, Socinski MA, Garon EB, et al. PointBreak: a randomized phase III study of pemetrexed plus carboplatin and bevacizumab followed by maintenance pemetrexed and bevacizumab versus paclitaxel plus carboplatin and bevacizumab followed by maintenance bevacizumab in patients with stage IIIB or IV nonsquamous non-small-cell lung cancer. J Clin Oncol 2013;31:4349-57.

13. Zukin M, Barrios CH, Pereira JR, et al. Randomized phase III trial of single-agent pemetrexed versus carboplatin and pemetrexed in patients with advanced non-small-cell lung cancer and Eastern Cooperative Oncology Group performance status of 2. J Clin Oncol 2013;31:2849-53.

14. Scagliotti GV, Parikh P, von Pawel J, et al. Phase III study comparing cisplatin plus gemcitabine with cisplatin plus pemetrexed in chemotherapy-naive patients with advanced-stage non-small-cell lung cancer. J Clin Oncol 2008;26:3543-51.

15. Schuette WH, Gröschel A, Sebastian M, et al. A randomized phase II study of pemetrexed in combination with cisplatin or carboplatin as first-line therapy for patients with locally advanced or metastatic non-small-cell lung cancer. Clin Lung Cancer 2013;14:215-23.

16. Blanchard EM, Moon J, Hesketh PJ, et al. Comparison of platinum-based chemotherapy in patients older and younger than 70 years: an analysis of Southwest Oncology Group Trials 9308 and 9509. J Thorac Oncol 2011;6:115-20.

17. McKeage MJ. Comparative adverse effect profiles of platinum drugs. Drug Saf 1995;13:228-44.

18. Piacentini P, Greco F, Mercanti A, et al. Platinum doublets as first-line treatment for elderly patients with advanced non-small cell lung cancer. Tumori 2013;99:650-5.

19. Cortellini A, Gambale E, Cannita K, et al. Multicentric retrospective analysis of platinum-pemetrexed regimens as first-line therapy in non-squamous non-small cell lung cancer patients: A "snapshot" from clinical practice. Thorac Cancer 2018;9:241-52.

20. Langer CJ, Socinski MA, Patel JD, et al. Isolating the role of bevacizumab in elderly patients with previously untreated nonsquamous non-small cell lung cancer: secondary analyses of the ECOG 4599 and PointBreak trials. Am J Clin Oncol 2016;39:441-7.

21. Tam TC, Ho JC, Wong MK, et al. Treatment outcomes in elderly with advanced-stage non-small cell lung cancer. Lung 2013;191:645-54.

22. Ramalingam SS, Dahlberg SE, Langer CJ, et al. Outcomes for elderly, advanced-stage non small-cell lung cancer patients treated with bevacizumab in combination with carboplatin and paclitaxel: analysis of Eastern Cooperative Oncology Group Trial 4599. J Clin Oncol 2008;26:60-5.

23. Mellema WW, van der Hoek D, Postmus PE, et al. 
Retrospective evaluation of thromboembolic events in patients with non-small cell lung cancer treated with platinum-based chemotherapy. Lung Cancer 2014;86:73-7.

24. Zahn MO, Linck D, Losem C, et al. AVAiLABLE NISAVASTIN® in lung cancer treatment in routine oncology practice in Germany. BMC Cancer 2019;19:433.

25. Niho S, Kunitoh H, Nokihara H, et al. Randomized

Cite this article as: Chen L, Kim JS, San Antonio B, Zhu YE, Mitchell L, John W. Safety outcomes in advanced non-smallcell lung cancer patients treated with first-line platinum-based regimens in the United States. J Thorac Dis 2019;11(11):44744483. doi: $10.21037 /$ jtd.2019.11.11 phase II study of first-line carboplatin paclitaxel with or without bevacizumab in Japanese patients with advanced non-squamous non-small-cell lung cancer. Lung Cancer 2012;76:362-7.

26. Russo AE, Priolo D, Antonelli G, et al. Bevacizumab in the treatment of NSCLC: patient selection and perspectives. Lung Cancer (Auckl) 2017;8:259-69. 
Table S1 The incidence of the use of supportive care drugs in the treatment population

\begin{tabular}{|c|c|c|c|c|c|c|c|c|c|c|c|c|c|c|c|c|c|c|}
\hline \multirow{2}{*}{$\begin{array}{l}\text { Types of } \\
\text { supportive care }\end{array}$} & \multicolumn{3}{|c|}{ Carb/Pacl $(\mathrm{N}=3,009)$} & \multicolumn{3}{|c|}{ Carb/Pacl/Bev (N=531) } & \multicolumn{3}{|c|}{ Carb/Peme $(N=1,625)$} & \multicolumn{3}{|c|}{ Carb/Peme/Bev (N=735) } & \multicolumn{3}{|c|}{ Cisp/Peme ( $N=357)$} & \multicolumn{3}{|c|}{ Doc/Carb (N=355) } \\
\hline & $n$ & IP (95\% Cl) & $\begin{array}{l}\text { IR }(95 \% \mathrm{Cl}) \text { per } \\
100 \text { person-years }\end{array}$ & $\mathrm{n}$ & $\mathbb{I P}(95 \% \mathrm{Cl})$ & $\begin{array}{l}\text { IR }(95 \% \mathrm{Cl}) \text { per } \\
100 \text { person-years }\end{array}$ & n & IP (95\% Cl) & $\begin{array}{l}\text { IR }(95 \% \mathrm{Cl}) \text { per } \\
100 \text { person-years }\end{array}$ & $n$ & IP (95\% Cl) & $\begin{array}{l}\text { IR (95\% Cl) per } \\
100 \text { person-years }\end{array}$ & $\mathrm{n}$ & $\mathrm{IP}(95 \% \mathrm{Cl})$ & $\begin{array}{l}\text { IR }(95 \% \mathrm{Cl}) \text { per } \\
100 \text { person-years }\end{array}$ & $\mathrm{n}$ & $\mathbb{I P}(95 \% \mathrm{Cl})$ & $\begin{array}{l}\text { IR (95\% Cl) per } \\
100 \text { person-years }\end{array}$ \\
\hline $\begin{array}{l}\text { Any Supportive } \\
\text { Care Drugs }\end{array}$ & 2,820 & $\begin{array}{c}93.70 \% \\
(0.929,0.945)\end{array}$ & $\begin{array}{c}1,788.55 \\
(1,722.54,1,854.56)\end{array}$ & 512 & $\begin{array}{c}96.40 \% \\
(0.948,0.98)\end{array}$ & $\begin{array}{c}4,471.62 \\
(4,084.28,4,858.96)\end{array}$ & 1,519 & $\begin{array}{c}93.50 \% \\
(0.923,0.947)\end{array}$ & $\begin{array}{c}2,107.09 \\
(2,001.13,2,213.05)\end{array}$ & 703 & $\begin{array}{c}95.60 \% \\
(0.94,0.972)\end{array}$ & $\begin{array}{c}5,046.66 \\
(4,673.6,5,419.7)\end{array}$ & 342 & $\begin{array}{c}95.80 \% \\
(0.936,0.98)\end{array}$ & $\begin{array}{c}2,172.81 \\
(1,942.53,2,403.09)\end{array}$ & 349 & $\begin{array}{c}98.30 \% \\
(0.969,0.997)\end{array}$ & $\begin{array}{c}6,155.2 \\
(5,509.42,6,800.98)\end{array}$ \\
\hline G-CSF & 1,177 & $\begin{array}{c}39.10 \% \\
(0.373,0.409)\end{array}$ & $\begin{array}{c}95.99 \\
(90.5,101.48)\end{array}$ & 237 & $\begin{array}{c}44.60 \% \\
(0.403,0.489)\end{array}$ & $\begin{array}{c}200.92 \\
(175.34,226.5)\end{array}$ & 1,016 & $\begin{array}{c}62.50 \% \\
(0.601,0.649)\end{array}$ & $\begin{array}{c}276.13 \\
(259.16,293.1)\end{array}$ & 478 & $\begin{array}{c}65.0 \% \\
(0.615,0.685)\end{array}$ & $\begin{array}{c}392.87 \\
(357.65,428.09)\end{array}$ & 193 & $\begin{array}{c}54.10 \% \\
(0.49,0.592)\end{array}$ & $\begin{array}{c}134.07 \\
(115.16,152.98)\end{array}$ & 173 & $\begin{array}{c}48.70 \% \\
(0.434,0.54)\end{array}$ & $\begin{array}{c}149.33 \\
(127.08,171.58)\end{array}$ \\
\hline ESA & 791 & $\begin{array}{c}26.30 \% \\
(0.247,0.279)\end{array}$ & $\begin{array}{c}49.67 \\
(46.2,53.14)\end{array}$ & 77 & $\begin{array}{c}14.50 \% \\
(0.116,0.174)\end{array}$ & $\begin{array}{c}35.1 \\
(27.26,42.94)\end{array}$ & 429 & $\begin{array}{c}26.40 \% \\
(0.242,0.286)\end{array}$ & $\begin{array}{c}63.67 \\
(57.65,69.69)\end{array}$ & 164 & $\begin{array}{c}22.30 \% \\
(0.194,0.252)\end{array}$ & $\begin{array}{c}60.83 \\
(51.52,70.14)\end{array}$ & 68 & $\begin{array}{c}19.00 \% \\
(0.149,0.231)\end{array}$ & $\begin{array}{c}26.6 \\
(20.27,32.93)\end{array}$ & 112 & $\begin{array}{c}31.50 \% \\
(0.266,0.364)\end{array}$ & $\begin{array}{c}57.82 \\
(47.12,68.52)\end{array}$ \\
\hline
\end{tabular}

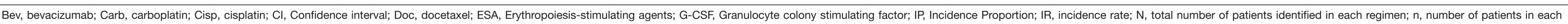
category; Pacl, paclitaxel; Peme, pemetrexed.

Table S2 The incidence of adverse events in the treatment population

\begin{tabular}{|c|c|c|c|c|c|c|c|c|c|c|c|c|c|c|c|c|c|c|}
\hline \multirow[b]{2}{*}{ Adverse Events } & \multicolumn{3}{|c|}{ Carb/Pacl $(\mathrm{N}=3,009)$} & \multicolumn{3}{|c|}{ Carb/Pacl/Bev (N=531) } & \multicolumn{3}{|c|}{ Carb/Peme ( $N=1,625)$} & \multicolumn{3}{|c|}{ Carb/Peme/Bev ( $(\mathrm{N}=735)$} & \multicolumn{3}{|c|}{ Cisp/Peme (N=357) } & \multicolumn{3}{|c|}{ Doc/Carb ( $N=355)$} \\
\hline & $\mathrm{n}$ & $\mathbb{P}(95 \% \mathrm{Cl})$ & $\begin{array}{l}\text { IR (95\% CI) per } 100 \\
\text { person-years }\end{array}$ & $n$ & IP (95\% Cl) & $\begin{array}{l}\text { IR (95\% CI) per } 100 \\
\text { person-years }\end{array}$ & $n$ & IP (95\% Cl) & $\begin{array}{l}\text { IR }(95 \% \mathrm{Cl}) \text { per } 100 \\
\text { person-years }\end{array}$ & n & IP $(95 \% \mathrm{CI})$ & $\begin{array}{l}\text { IR }(95 \% \mathrm{Cl}) \text { per } \\
100 \text { person-years }\end{array}$ & $\mathrm{n}$ & IP (95\% Cl) & $\begin{array}{l}\text { IR }(95 \% \mathrm{Cl} \text { ) per } \\
100 \text { person-years }\end{array}$ & $n$ & IP (95\% Cl) & $\begin{array}{l}\text { IR }(95 \% \mathrm{Cl}) \text { per } \\
100 \text { person-years }\end{array}$ \\
\hline Constipation & 46 & $1.50 \%(0.011,0.019)$ & $2.29(1.62,2.96)$ & 16 & $3.00 \%(0.016,0.044)$ & $6.54(3.33,9.75)$ & 24 & $1.50 \%(0.009,0.021)$ & $2.61(1.57,3.65)$ & 11 & $1.50 \%(0.007,0.023)$ & $3.42(1.4,5.44)$ & 10 & $2.80 \%(0.01,0.046)$ & $3.43(1.31,5.55)$ & 1 & $0.30 \%(0,0.009)$ & $0.39(0,1.15)$ \\
\hline Hemorrhage & 39 & $1.30 \%(0.009,0.017)$ & $1.93(1.32,2.54)$ & 8 & $1.50 \%(0.005,0.025)$ & $3.27(1,5.54)$ & 18 & $1.10 \%(0.005,0.017)$ & $1.95(1.05,2.85)$ & 3 & $0.40 \%(0,0.008)$ & $0.93(0,1.99)$ & 5 & $1.40 \%(0.002,0.026)$ & $1.7(0.21,3.19)$ & 4 & $1.10 \%(0,0.023)$ & $1.54(0.03,3.05)$ \\
\hline Hypertension & 36 & $1.20 \%(0.008,0.016)$ & $1.78(1.19,2.37)$ & 12 & $2.30 \%(0.009,0.037)$ & $4.95(2.15,7.75)$ & 13 & $0.80 \%(0.004,0.012)$ & $1.41(0.65,2.17)$ & 10 & $1.40 \%(0.006,0.022)$ & $3.14(1.2,5.08)$ & 5 & $1.40 \%(0.002,0.026)$ & $1.7(0.21,3.19)$ & 7 & $2.00 \%(0.006,0.034)$ & $2.71(0.71,4.71)$ \\
\hline Anorexia & 35 & $1.20 \%(0.008,0.016)$ & $1.72(1.15,2.29)$ & 9 & $1.70 \%(0.005,0.029)$ & $3.65(1.26,6.04)$ & 17 & $1.00 \%(0.006,0.014)$ & $1.85(0.97,2.73)$ & 3 & $0.40 \%(0,0.008)$ & $0.92(0,1.96)$ & 5 & $1.40 \%(0.002,0.026)$ & $1.68(0.21,3.15)$ & 2 & $0.60 \%(0,0.014)$ & $0.77(0,1.83)$ \\
\hline Edema & 29 & $1.00 \%(0.006,0.014)$ & $1.42(0.91,1.93)$ & 7 & $1.30 \%(0.003,0.023)$ & $2.84(0.74,4.94)$ & 20 & $1.20 \%(0.006,0.018)$ & $2.18(1.22,3.14)$ & 2 & $0.30 \%(0,0.007)$ & $0.61(0,1.45)$ & 8 & $2.20 \%(0.006,0.038)$ & $2.75(0.85,4.65)$ & 0 & $0.00 \%$ & 0 \\
\hline Pain & 16 & $0.50 \%(0.003,0.007)$ & $0.78(0.39,1.17)$ & 7 & $1.30 \%(0.003,0.023)$ & $2.84(0.74,4.94)$ & 1 & $0.10 \%(0,0.003)$ & $0.11(0,0.33)$ & 1 & $0.10 \%(0,0.003)$ & $0.31(0,0.92)$ & 3 & $0.80 \%(0,0.018)$ & $1.01(0,2.15)$ & 3 & $0.80 \%(0,0.018)$ & $1.16(0,2.47)$ \\
\hline
\end{tabular}

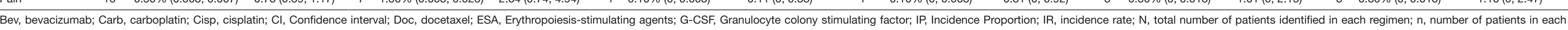

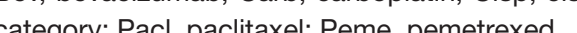

